技術論文

DOI:10.5139/JKSAS.2010.38.10.1026

\title{
$\mathrm{BLDC}$ 모터로 구동되는 액체 추진제 로켓엔진용 극저온 추력제어밸브 개발
}

정태규*, 이수용**

\section{Development of BLDC Motor Driven Cryogenic Thrust Control Valve for Liquid Propellant Rocket Engine}

Taekyu Jung* and Sooyong Lee**

\begin{abstract}
This paper summarizes the activities performed for the development of a BLDC(Brushless Direct Current) motor driven cryogenic thrust control valve with application to KSLV-II rocket engine. The developed thrust control valve can modulate the flow rate of liquid oxygen under cryogenic temperature of $90 \mathrm{~K}$ and high pressure of 113.2 bar with the help of electro-mechanical actuator driven by a BLDC motor. This valve can be applied to an engine combustion test after minor change because all development certification test have been performed successfully.

\section{초 록}

본 논문에서는 KSLV-II의 로켓엔진에 사용될 BLDC 모터로 구동되는 극저온 추력제어 밸브의 개발 과정 및 결과를 소개하였다. 개발된 추력제어밸브는 $90 \mathrm{~K}$ 의 극저온, $113.2 \mathrm{bar}$ 의 고압 환경에서 액체산소의 유량을 BLDC 모터로 작동되는 밸브 구동기를 통해 조절할 수 있다. 추력제어밸브는 모든 개발 인증시험을 통과하였으므로 향후 일부 하드웨어 수정 후, 엔진 연소시험에 적용이 가능하다.
\end{abstract}

Key Words : Thrust control(추력제어), LRE(액체 로켓엔진), Control valve(제어밸브), BLDC motor(브러쉬레스 직류모터)

\section{I. 서 론}

인공위성을 원하는 궤도에 진입시키기 위해서 는 발사체의 속도를 정확하게 제어해야 하는데, 이때 발사체 속도를 제어하기 위해서는 로켓엔진 의 추력을 제어해야 한다. 로켓엔진의 추력 제어 는 비행 중에 위성 및 우주인 보호를 위해 비행 가속도 및 발사체 공력가열 등을 제한하기 위해

† 2010년 5월 20일 접수 2010년 9월 7일 심사완료

* 정회원, 한국항공우주연구원 교신저자, E-mail : tkjung@kari.re.kr 대전광역시 유성구 어은동 45 번지

** 정회원, 한국항공우주연구원
서도 사용된다 ${ }^{(1)}$. 또한 발사체의 비행가속도에 의 한 추진제 가압 압력 변화와 추진제 탱크의 공력 가열로 인한 추진제 밀도 변화로 인한 엔진의 추 력 변화 등을 보정하기 위해서도 추력 제어가 필 요하다 ${ }^{(2)}$.

액체 추진제 로켓엔진의 추력을 제어하기 위 해서 일반적으로 사용하는 방식은 로켓엔진의 가 스발생기 또는 예연소기로 유입되는 산화제나 연 료의 유량을 제어밸브를 사용하여 제어하는 것이 다. 일반적으로 로켓엔진에 사용되는 제어밸브는 직류 전기모터를 사용하는 구동방식이 주로 사용 된다 ${ }^{(3,4)}$. 유압 및 공압 구동기의 경우, 유압 및 공압 시스템이 별도로 필요하기 때문에 시스템이 


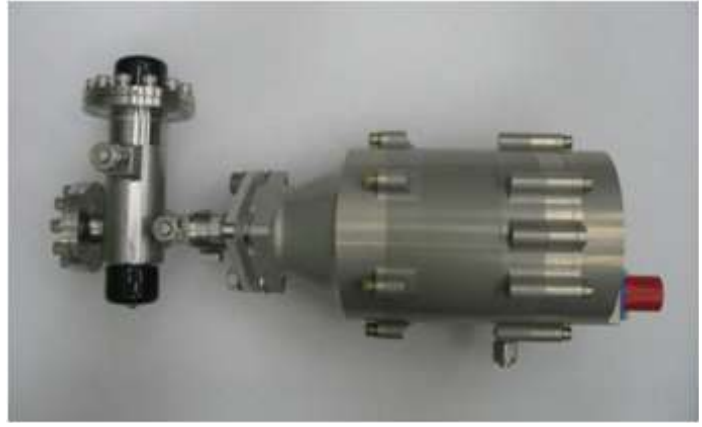

Fig. 1. Prototype of thrust control valve

복잡해지고 배관으로 연결해야 하므로 누설 등의 문제가 발생할 소지가 있다. 또한 설계 변경이 필요할 경우, 유공압 시스템도 같이 변경해야 하 는 단점이 있다. 그러나 전기모터 구동기는 시스 템이 간단하고 설계 변경 시, 전압 조절 등 전기 적 조절을 통해 설계 변경이 용이하므로 설계 자 유도가 크다. 또한 제어기를 통한 되먹임 제어의 구현이 쉽다는 장점이 있다. 이와 같은 직류 전 기모터를 사용한 제어밸브는 발사체 선진국인 러 시아, 미국, 유럽 등에서는 활발히 개발되어 로켓 엔진에 사용되고 있다. 반면에 국내에서는 산업 용 제어밸브는 어느 정도 기술 축적이 이뤄졌다 고 볼 수 있으나 로켓엔진용 제어밸브, 특히 극 저온용 제어밸브의 개발은 상대적으로 늦게 시작 되었다. 그러나 항공우주연구원에서 수행한 연구 ${ }^{(8-9)}$ 를 통해 관련 기술의 축적이 빠르게 이루어져 왔다.

본 논문은 KSLV-II의 주 엔진으로 개발 중인, 등유-액체산소를 추진제로 사용하는 75 톤급 개방 형 로켓엔진의 추력제어를 위해, 가스발생기로 유입되는 극저온 추진제인 액체산소의 유량을 제 어하는 추력제어밸브[Fig. 1]의 시제품 개발과 개 발 인증시험 결과를 다루었다. Fig. 1에서 좌측이 유량제어부이고 우측이 모터 제어방식의 구동기 인 EMA(Electro-Mechanical Actuator)이다.

\section{II. 설계 및 구성}

\section{1 추력제어밸브}

Fig. 2는 추력제어밸브의 유량제어부 구성도이 다. EMA와 연결된 회전축이 회전하면 슬리브가 좌우로 이동하면서 슬리브와 플런저 사이의 유로 면적을 변경하여 액체 산소의 유량을 조절하게 된다. 이와 같이 유체의 유동방향과 스로틀의 역 할을 하는 슬리브의 이동 방향이 같은 축을 이루
Table 1. Specification of TCV

\begin{tabular}{ccc}
\hline Requirement & Unit & Value \\
\hline Flow diameter & $\mathrm{mm}$ & 14.4 \\
Medium & - & LOx \\
Flow rate(max.) & $\mathrm{kg} / \mathrm{s}$ & 4.0 \\
Pressure(max.) & $\mathrm{bar}$ & 113.2 \\
Temperature & $\mathrm{K}$ & $90-300$ \\
Voltage & $\mathrm{V}$ & 24 \\
External leakage & $\mathrm{scc} / \mathrm{sec} \mathrm{GHe}$ & $<10^{-3}$ \\
Weight & $\mathrm{kg}$ & 3.1 \\
Gear ratio & - & 1,584 \\
\hline
\end{tabular}

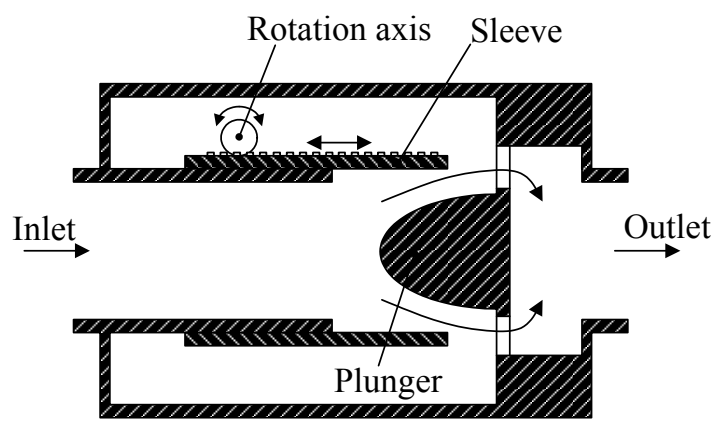

Fig. 2. Configuration of flow control part

는 밸브를 동축형 밸브(In-line co-axial valve)라 한다 ${ }^{(5)}$. 동축형 밸브는 슬리브의 두께가 얇으므로 슬리브 양단에 작용하는 압력차에 의해 발생하는 유체력이 볼밸브나 글로브밸브 등에 비해 매우 작다. 따라서 구동기의 요구 파워가 작으므로 결 과적으로 구동기의 크기 및 무게를 줄일 수 있 다. 또한 유량제어 특성도 좋기 때문에 로켓 엔 진용 제어밸브로서 많이 사용되고 있다 ${ }^{(3,5)}$. 한편, $\mathrm{EMA}$ 는 BLDC 모터, 감속기어, 토크리미터, 포텐 셔미터 등으로 구성되어 있다. 토크리미터는 기 계적 문제로 인해 밸브가 작동하지 않는 경우, 일정 토크 이상에서 토크리미터가 헛돌게 하여 기어트레인 및 모터의 손상을 방지한다. 포텐셔 미터는 기어 최종축의 회전각을 측정하여 밸브의 개도를 제어할 수 있게 한다. 추력제어밸브(TCV) 의 주요 제원은 Table 1 과 같다.

\section{2 제어기}

현재 KSLV-II는 설계 개념상, 엔진 추력을 지 상 시험에서만 설계값으로 맞추기 위해 추력제어 밸브를 작동시키는 것으로 되어있다. 따라서 추 력제어밸브 제어기[Fig. 3]는 비행용이 아닌 지상 시험용이므로 산업용 기기를 이용하여 구성하였 다. 제어기는 추력제어밸브를 포함하여 세 개의 


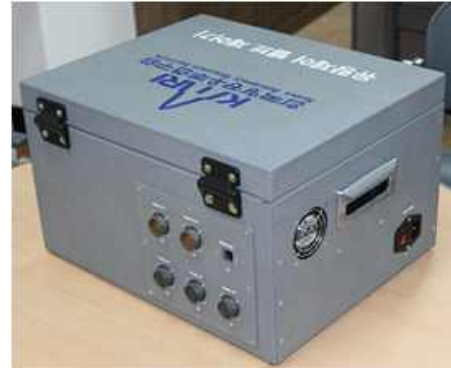

Fig. 3. Photograph of controller

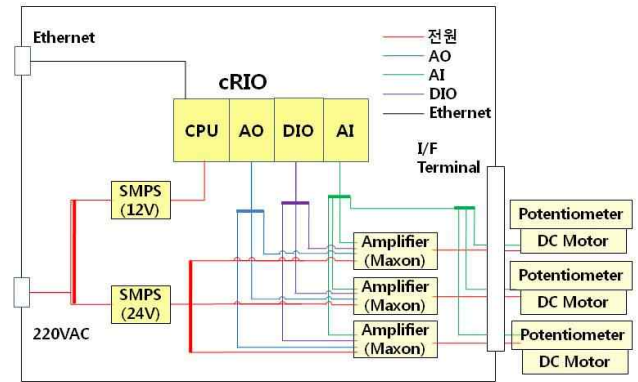

Fig. 4. Controller configuration

제어밸브를 동시에 제어할 수 있다. 따라서 Fig. 4 와 같이 BLDC 모터 제어를 위한 세 개의 모터 드라이브(Amplifier- Maxon DECV 50/5)와 리얼 타임 콘트롤러인 NI사의 cRIO 9014, 디지털 및 아날로그 신호 입출력 모듈 등으로 구성하였다.

제어 프로그램이 설치된 컴퓨터는 cRIO와 이 더넷 통신을 통하여 데이터 및 제어 명령을 송수 신 한다. 제어기는 제어밸브의 운전 속도 및 위 치를 PID 제어를 통해 제어한다. 운전 속도는 BLDC 모터에 내장된 홀센서 신호를 이용하여 제어하고 위치 제어는 제어밸브의 포텐셔미터 신 호를 이용하여 제어밸브 개도를 제어한다.

\section{III. 개발 인증 시험}

\section{1 고유유량특성 시험}

추력제어밸브는 일종의 유량제어밸브이다. 유 량제어밸브의 유량특성을 나타내는 지표로서 고 유유량특성이 사용된다 ${ }^{(6,7)}$. 고유유량특성은 제어 밸브가 장착되는 설비의 특성과 관계없이 제어밸 브 자체가 가지는 고유한 유량특성을 나타내며 식(1)과 같이 밸브 개도에 따른 유량계수, $K_{v}$ 로 표현한다.

$$
K_{v}=Q \sqrt{\frac{G}{\Delta P}}
$$

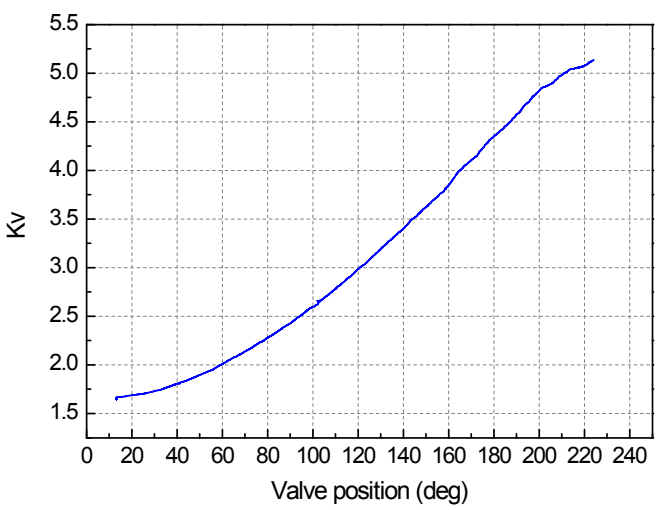

Fig. 5. Inherent flow characteristic of TCV

상기 식에서 $Q$ 는 유량 $(\mathrm{m} 3 / \mathrm{h}), \mathrm{G}$ 는 유체의 비중, $\Delta \mathrm{P}$ 는 밸브 입출구 압력차(bar)이다.

Fig. 5는 추력제어밸브의 고유유량특성 시험 결과이다. 밸브 회전축이 $13 \sim 220 \mathrm{deg}$ 로 회전할 때, 해당 유량계수 $(\mathrm{Kv})$ 는 1.7 5.1의 값을 가진다. 유량계수의 설계값인 1.5 6.2과는 약간의 오차를 가지는데, 이는 Fig. 2의 제어밸브 플런저 형상 변경을 통해 개선이 가능하다.

한편, Fig. 5와 같은 고유유량특성의 곡선 형태도 플런저 형상 변경을 통해 조절이 가능하다. 고유 유량특성을 적절히 설계하면 엔진시스템의 비선 형성을 제어밸브에서 보상하여 밸브 개도 변화에 따른 엔진의 추력 변화 특성을 선형적인 관계로 만들 수 있다.

\section{2 내압 및 기밀 시험(상온, 극저온)}

최대 작동 압력(MEOP)의 1.5 배인 $170 \mathrm{bar}$ 에서 물을 이용하여 내압 시험을 수행하였다. 내압 시 험에서 소성 변형과 외부 누설이 없었다. 한편, 기밀시험은 $\mathrm{MEOP}$ 의 1.1 배인 $125 \mathrm{bar}$ 에서 상온 및 극저온 환경에서 수행하였다. 상온 기밀시험 은 기체 헬륨을 사용하여 수행하였고 누설이 없 었다. 극저온 환경에서의 기밀 성능은 제어밸브 를 Fig. 6과 같이 액체 질소(77K)에 담그고 기체

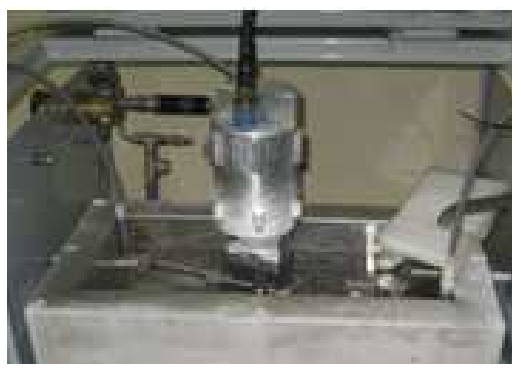

Fig. 6. Cryogenic test 
헬륨을 125 bar로 밸브 유로부에 주입하여 외부 누설 여부를 파악하였다. 밸브 플렌지[Fig. 1 참 조]의 부위에서 약간의 누설이 발생하였다. 본 시 제품은 개발 시제이므로 유지 보수 및 플런저 교 체를 위해 밸브 바디에 플렌지 체결 방식을 사용 하였다. 그러나 실제 비행용 추력제어밸브는 플 렌지 없이 용접으로 접합을 하게 되므로 해당 부 위의 누설은 원천적으로 없을 것으로 기대된다.

\section{3 진동 환경시험}

발사체는 비행 중에 극심한 진동을 받게 된다. 이러한 진동 환경에서 추력제어밸브의 정상 작동 및 파손 여부를 파악하기 위해 Fig. 7과 같이 가 진기를 이용하여 진동 환경시험을 수행하였다.

진동 환경시험으로 준-정적 가속도, 랜덤 진동, 정현 진동, 반-정현파 충격시험 등을 수행하였다. 시험 진행 중 및 시험 후, 밸브가 정상적으로 작 동하였으며 파손 부위가 없었다.

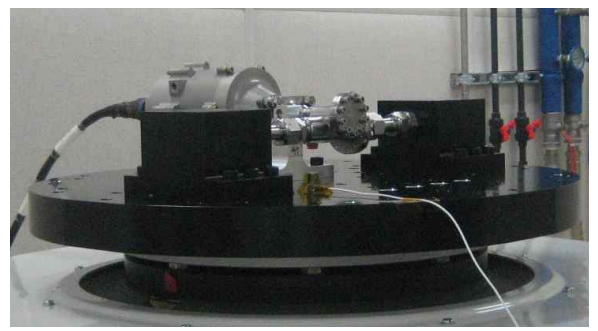

Fig. 7. Vibration test

\section{4 전자기파 환경시험}

발사체에는 추력제어밸브 이외에도 여러 전자 장비가 탑재되어 있으므로 추력제어밸브로 인한 EMI 문제를 고려해야 한다. 따라서 추력제어밸 브의 모터 구동 시 발생하는 전자기파의 강도를 MIL-STD-461E(RE102) 시험 기준에 의거하여 측

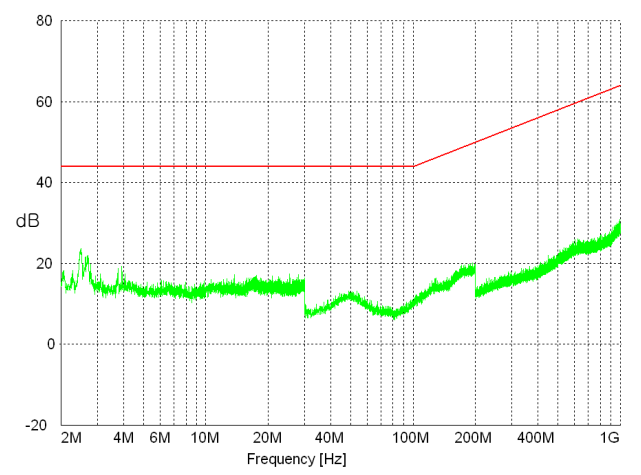

Fig. 8. RE102 test result
정하였다.

Fig. 8의 시험 결과와 같이 KSLV-I 2단 로켓의 RE102 기준으로 사용된 "Fixed Wing External $(2 \mathrm{MHz} \sim 18 \mathrm{GHz}) "$ 기준 값(위)보다 추력제어밸브 의 $\mathrm{EMI}$ 강도(아래)가 $20 \mathrm{~dB}$ 이상 낮은 것으로 나 타났으므로 추력제어밸브로 인한 EMI 문제는 없 을 것으로 판단된다.

\section{5 진공 환경시험}

발사체는 비행 중에 진공 환경에 노출되므로 진공 환경에서 추력제어밸브의 작동 성능 및 이 상 유무를 파악하기 위해 Fig. 9와 같이 진공 환 경시험을 수행하였다. 진공도 $10^{-3}$ torr에서 6분간 추력제어밸브를 동작하였을 때 정상 작동 하였으 며 하드웨어에 손상이 발생하지 않았다. 참고로 본 추력제어밸브는 BLDC 모터, 즉 브러쉬가 없 는 직류 모터를 사용하였기 때문에 진공 환경에 서 자주 발생하는 코로나 방전에 의한 모터 브러 쉬의 손상 가능성은 없다.

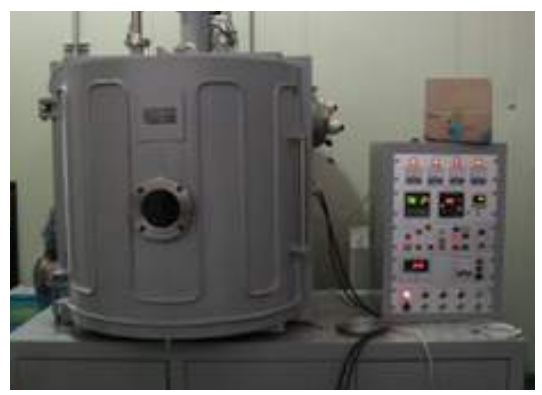

Fig. 9. Vacuum test equipment

\section{6 내구성 시험}

추력제어밸브의 내구성을 파악하기 위해 상온 에서 50회 왕복 작동 후 기밀시험 및 고유유량특 성 시험을 수행하였다. 또한 극저온 환경(액체질 소, $77 \mathrm{~K})$ 에서 100 회 왕복 작동 후, 극저온 기밀 시험 및 상온 고유유량특성 시험을 수행하였다. 상온 내구성 시험 후에는 누설이 없었고 극저온 기밀은 3.2절과 동일하게 플렌지에서 누설이 발 생하였다. 고유유량특성은 내구성 시험 전의 값 과 비교 시, 목표 값인 $0.5 \%$ 변화율 내에 들었다.

\section{7 응답특성 시험}

추력제어밸브의 모터 회전수는 제어기에서 0 $5 \mathrm{~V}$ 의 제어 전압을 모터 드라이브로 전달하면 모 터가 1000 7500rpm으로 회전한다. 감속 기어비 가 1,584 이므로 밸브 회전축은 $3.8 ~ 28.4 \mathrm{deg} / \mathrm{s}$ 의 속도로 회전하게 된다. 


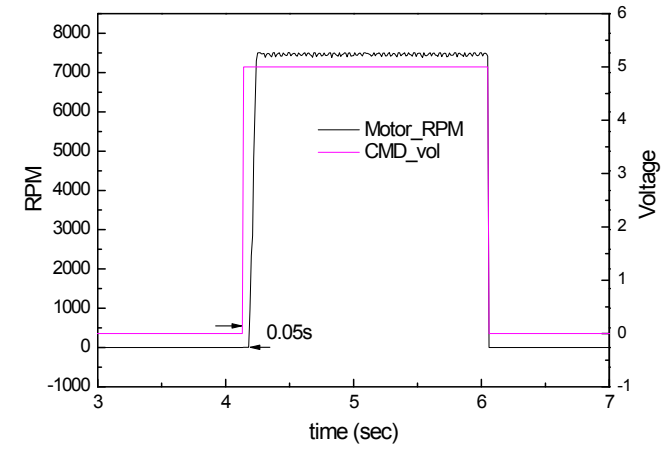

Fig. 10. Response test result

Fig. 10 은 제어 전압이 $5 \mathrm{~V}$ 일 때의 모터 회전 특성을 도시한 것이다. 제어 전압 입력 후, 0.05 초의 시간지연이 있는데, 이는 전기적인 지연으 로 제어 전압(CMD_vol)의 크기와는 상관없이 항 상 일정하다. 한편, 모터가 정지 상태에서 $7500 \mathrm{rpm}$ 까지 상승하는데 걸리는 시간은 0.07 초 이고 $7500 \mathrm{rpm}$ 에서 정지하는데 걸리는 시간은 0.01 초이다. 제어 전압 $(0 \sim 5 \mathrm{~V})$ 에 따른 상승 및 정 지 시간은 모두 동일하였다.

\section{IV. 결 론}

KSLV-II 주 엔진에 사용될 추력제어밸브의 시 제품을 개발하였다. 극저온 환경에서 플렌지 부 위의 누설을 제외하면 성능 및 환경시험 등의 모 든 개발 인증시험을 통과하였다. 단, 극저온 누설 의 경우, 향후 해당 부위를 플렌지가 아닌 용접 처리를 할 것이므로 본 연구를 통해 개발된 추력 제어밸브는 하드웨어 자체로는 엔진 연소시험에 적용이 가능하다. 단, 엔진 연소시험에 앞서 추력 제어 알고리즘을 개발하고 엔진 모사 설비를 이 용한 수류시험 등을 통해 추력제어 알고리즘에 대한 사전 검증이 필요하다. 따라서 향후, 추력제 어 알고리즘 설계에 대한 연구가 필요하다.

본 연구를 통해 획득한 극저온 추력제어밸브 의 설계, 제작 및 인증시험 기술은 향후 KSLV-II 엔진에 사용될 기타 밸브류의 개발에 큰 기여를 할 것으로 판단된다.

\section{후 기}

본 연구는 기초기술연구회 지원의 “미래 발사 체 핵심 요소기술 연구" 과제의 일부로 수행되었 습니다. 지원에 감사드립니다.

\section{참고문헌}

1) Sutton, G. P., "Rocket Propulsion Elements : An Introduction to the Engineering of Rockets", 6th Edition, John Wiley \& Son, 1992.

2) Glikman, B. F., "Automatic Control of Liquid Rocket Engines", Mashinostroyenie, Moscow, 1974 (In Russian).

3) MaCormick, $S$ and Garrison, M, "EM Actuated Cryogenic Valve for Engine Control", AIAA 2006-4881, 42nd AIAA/ASME/SAE /ASEE Joint Propulsion Conference \& Exhibit, ,California, 2006.

4) Borbouse, C., Jauquet, P. F., Bomal, J. C. and Promper, C., "Electronically Controlled Ball Valve: the LOx Valve of Vinci", 4th Intl Conference on Launcher Technology, Liege (Belgium), 2002.

5) Horstmann, M and Routh, M., "Status of Dasa Development of Motor Driven Valves", AIAA-99-2331, 35th AIAA/ASME/SAE/ASEE Joint Propulsion Conference \& Exhibit, Los Angeles, California, 1999.

6) Driskell, L., "Control-valve Selection and sizing", ISA, 1983.

7) Skousen, P. L., "Valve Handbook", McGraw-Hill, 1997.

8) 김영목, 정태규, 이중엽, 정영석, 한상엽, 권오성, 조규식, "로켓엔진 추력제어기술 개발", 3차년도 보고서, 한국항공우주연구원, 2006.

9) 김영목, 정태규, 이중엽, 정영석, 한상엽, 권오성, "로켓엔진 추력제어기술 개발", 4 차년도 보고서, 한국항공우주연구원, 2007. 